\title{
Kepuasan Perawat Setelah Melakukan Overan Sisi Pasien dengan Komunikasi SBAR
}

\author{
Idawati Manurung ${ }^{1}$, Giri Udani ${ }^{2}$ \\ Jurusan Keperawatan, Politeknik Kesehatan Tanjung Karang, Indonesia \\ Email: idawatimanurung@yahoo.com
}

\begin{abstract}
Nurse Satisfaction After Overaning the Patient's Side with SBAR Communication. Hospital service quality must be improved, one aspect is patient safety, its efforts are through increased effective communication. One of the indicators is communicates using the SBAR method. The handover between shift at the hospital has not carried out handover at the patient's side by using the SBAR method and has not been oriented to the patient's condition. Therefore nurses have not focused on the development of the condition of the patients and did not provide nurse satisfaction their nursing care performed. The study aimed to compare nurse satisfaction before and after bedside handover intervention with the SBAR method in the inpatient room. This research is quantitative with a cross-sectional design, the sample of all nurses in the inpatient room is 80 people. The results obtained before the intervention, the highest satisfaction is the need for self-actualization and after the highest satisfaction the need to have. The lowest satisfaction needs before and after the intervention are physiological needs. There is a significant difference between the satisfaction of respondents before and after the intervention. Bedside handover between shift is very useful and gives satisfaction to the nurses, must be carrying out nursing with guidance and supervision and giving rewards to the nurse who practices that when care the patients.
\end{abstract}

Keywords: Bedside handover, Satisfaction, SBAR communication

\begin{abstract}
Abstrak: Kepuasan Perawat Setelah Melakukan Overan Sisi Pasien dengan Komunikasi SBAR. Mutu pelayanan Rumah sakit harus ditingkatkan, salah satu aspeknya adalah keselamatan pasien, upayanya dengan melalui peningkatan komunikasi efektif. yang salah satu indikatornya melakukan komunikasi dengan memakai metoda SBAR. Overan dinas antar shif di rumah sakit belum melaksanakan overan disisi pasien dengan memakai prinsip metoda SBAR dan belum berorientasi pada kondisi pasien. Oleh karena itu perawat belum fokus pada perkembangan kondisi dan tidak memberikan kepuasan perawat atas keberhasilan asuhan keperawatan yang dilakukan. Penelitian bertujuan membandingkan kepuasan perawat sebelum dan sesudah intervensi metode overan sisi pasien dengan komunikasi SBAR di ruang rawat inap. Penelitian ini kuantitatif dengan rancangan cross sectional, populasi, seluruh perawat di ruangan rawat inap, sampel penelitian berjumlah 80 orang. Hasil penelitian didapatkan sebelum intervensi kepuasan yang paling tinggi adalah kebutuhan aktualisasi diri dan sesudah intervensi kepuasan yang paling tinggi adalah kebutuhan memiliki. Kepuasan kebutuhan yang paling rendah pada saat sebelum dan sesudah intervensi adalah kebutuhan fisiologis. Ada perbedaan yang bermakna antara kepuasan responden sebelum dan sesudah intervensi, overan dinas antar shif di sisi pasien sangat baik dan memberikan kepuasan pada perawat dalam melaksanakan asuhan keperawatan Saran untuk rumah sakit adalah, metode ini sebaiknya dilakukan dengan proses pembimbingan dan supervisi yang baik, serta perlu pemberian penghargaan pada para perawat yang telah menjalankannya.
\end{abstract}

Kata kunci: Overan sisi pasien, Kepuasan, Komunikasi SBAR

\section{PENDAHULUAN}

Manajemen pelayanan keperawatan, yang terkait erat dengan manajemen rumah sakit dan manajemen asuhan keperawatan yang berhubungan dengan profesi perawat yaitu berhubungan dengan proses keperawatan. (Nursalam, 2011). Ketidak puasan perawat pada kinerjanya membuat perawat tidak bekerja keras, melakukan banyak pelanggaran secara manajemen (tingginya absensi, tidak patuh aturan, tidak disiplin) dan banyak melanggar standar-standar kinerja secara profesi yang bisa membahayakan pasien. Bila perawat puas dalam melaksanakan kinerjanya dalam asuhan keperawatan maka pada akhirnya akan 
memperbaiki mutu pelayanan keperawatan dan meningkatkan kepuasan pasien.

Rumah sakit harus terus meneruskan meningkatkan mutu pelayanannya, salah satu aspeknya adalah keselamatan pasien. Berdasarkan Standar Nasional Akreditasi Rumah Sakit (SNARS), salah satu upaya meningkatkan keselamatan pasien adalah melalui peningkatan komunikasi yang efektif. Komunikasi efektif, salah satu indikatornya melakukan komunikasi dengan memakai prinsip metoda SBAR (Situation, Background, Assesement, Recomendation). Pemakaian komunikasi ini dilakukan pada saat overan antar shift, transfer pasien antar ruangan dan pelaporan kondisi pasien. Selama masa perawatan di rumah sakit, pasien bisa saja mengalami perpindahan dari beberapa unit ruang rawat, seperti dari ruang gawat darurat, kamar operasi, ruang perawatan dan unit rawat jalan. Pasien dirawat bermacammacam profesi tim kesehatan dan harus menghadapi tim-tim perawatan yang berbeda setiap dinas (shift). Kondisi ini membutuhkan proses overan yang terstruktur dan terprogram dengan baik dan menunjang keselamatan pasien (Dewi, 2012). Ada hubungan kepatuhan perawat dalam handover antar shift terhadap keselamatan pasien. (Samakori, 2019).

RS. Imanuel di Bandar Lampung, telah mencapai Akreditasi Paripurna tahun 2016. Hasil pengamatan didapatkan bahwa ada perbedaan data yang disampaikan antara overan secara verbal dengan yang tertulis, dan komunikasi SBAR belum dilaksanakan saat overan antar shift, menunjukan bahwa komunikasi dalam overan belum baik, pengetahuan tentang overan masih belum baik, lingkungan untuk melaksanakan overan juga belum baik, serta format-format overan juga belum baik dan masih tidak seragam.

Hasil penelitian yang dilakukan peneliti pada tahun 2016 mengenai analisis perbedaan kepuasan perawat dan kepuasan pasien sebelum dan sesudah overan sisi pasien di Rumah Sakit Umum Daerah Demang Sepulau Raya dan di Rumah Sakit Umum Daerah A. Dadi Tjokrodipo menunjukkan ada perbedaan yang bermakna antara kepuasan sebelum dan sesudah metoda overan di sisi pasien dilakukan. Kepuasan perawat terhadap kinerja dan pelayanannya meningkat dan kepuasan pasien terhadap pelayanan dan pemulihannya meningkat. Overan sisi pasien adalah metode serah terima pasien antar shift yang dilakukan di sisi pasien. Tujuannya adalah meningkatkan komunikasi antar perawat dan komunikasi perawat dengan pasien. Hasil dari komunikasi ini adalah meningkatnya keselamatan pasien, kekambuhan berkurang, kepuasan perawat dan pasien meningkat serta keterlibatan pasien juga meningkat (Malfait, et al., 2018; Donna, et al., 2007). Tujuan penelitian ini adalah mengetahui kepuasan perawat setelah melakukan overan sisi pasien dengan komunikasi SBAR di ruang rawat inap.

\section{METODE}

Pada tahap awal penelitian ini, diadakan mengadakan persamaan persepsi dengan perawat ruangan dan staf supervisor yang digunakan untuk penelitian. Pre intervensi dilakukan dengan mengukur kepuasan perawat terhadap overan dengan kuesioner kepuasan terhadap pelaksanaan overan sisi pasien. Tahap Intervensi melaksanakan overan sisi pasien dengan komunikasi efektif SBAR selama satu bulan. di ruang rawat inap. Peneliti selama satu minggu mendampingi perawat melakukan overan baik pagi maupun siang, untuk selanjutnya dibimbing dan disupervisi kepala ruangan.

Supervisi pada saat overan akan mengarahkan perawat agar sesuai pedoman yang telah ditetapkan dan merupakan bentuk dukungan positif yang diberikan oleh kepala ruangan dan rekan kerja. Perawat merasa bangga dapat menunjukkan secara kongkret hasil pekerjaannya. Jika hasil pekerjaan tidak mendapat penghargaan akan menurunkan kepuasan kerja (Basri, 2018; Sumartyawati, 2018). Pengukuran post intervensi dengan kuesioner yang sama dengan pre intervensi setelah satu bulan pelaksanaan overan sisi pasien dengan komunikasi efektif SBAR. Penelitian ini dilaksanakan pada SeptemberNovember 2018, di Ruang Rawat, RS Imanuel, Bandar Lampung yang sudah melaksanakan metoda perawat penanggungjawab pasien (PPJP).

Analisa bivariat dilakukan mengukur perbedaan kepuasan perawat sebelum dan setelah intervensi overan sisi pasien dengan komunikasi SBAR. Uji memakai metoda dependent sample $t$ test (Hastono, 2007; Notoatmodjo, 2011).

Penelitian ini telah mendapatkan Ethical Clearance No 246/EC/KEP-TJK/IX/2018 dari Komisi Etik Penelitian Kesehatan Politeknik Kesehatan Tanjung Karang.

\section{HASIL}

Hasil penelitian menunjukkan umur responden paling banyak pada tingkat dewasa awal, 49 orang atau $61,3 \%$. Jenis kelamin paling 
banyak perempuan dengan 67 orang atau $43,8 \%$. Masa kerja responden, paling banyak pada di rentang lebih dari 24 bulan, kategori lama yaitu 44 orang atau $55 \%$. Hasil penelitian pada saat pre intervensi, kepuasan yang paling tinggi adalah kebutuhan aktualisasi diri, 64 orang $(80 \%)$, sedangkan pada saat post intervensi, kepuasan yang paling tinggi adalah kebutuhan memiliki, 53 orang $(66,3 \%)$. Kepuasan kebutuhan yang paling rendah pada saat pre intervensi dan pada saat post intervensi adalah kebutuhan fisiologis. Hal ini terlihat pada tabel 1 .

Tabel 1. Kepuasan Responden Berdasarkan Kebutuhan Dasar Manusia

\begin{tabular}{lcccccccc}
\hline \multirow{2}{*}{ Kebutuhan } & \multicolumn{4}{c}{ Pre Intervensi } & \multicolumn{4}{c}{ Post Intervensi } \\
\cline { 2 - 9 } & \multicolumn{3}{c}{ Tidak Puas } & \multicolumn{3}{c}{ Puas } & \multicolumn{3}{c}{ Tidak Puas } & \multicolumn{1}{c}{ Puas } \\
\cline { 2 - 10 } & F & $\mathbf{( \% )}$ & F & $\mathbf{( \% )}$ & F & $(\%)$ & F & $(\boldsymbol{\%})$ \\
\hline Fisiologis & 33 & 41,3 & 47 & 58,8 & 31 & 38,8 & 49 & 61,3 \\
Rasa Aman & 23 & 28,7 & 57 & 71,3 & 30 & 37,5 & 50 & 62,5 \\
Memiliki & 15 & 18,8 & 65 & 80,0 & 27 & 33,8 & 53 & 66,3 \\
Harga Diri & 31 & 38,8 & 49 & 61,3 & 32 & 40,0 & 48 & 60,0 \\
Aktualisasi diri & 16 & 20,0 & 64 & 81,3 & 31 & 38,8 & 49 & 61,3 \\
\hline
\end{tabular}

Hasil penelitian juga menunjukkan bahwa pada saat pre intervensi, paling tinggi responden puas, 55 orang atau $68,8 \%$, sedangkan pada saat post intervensi, paling tinggi responden puas, 49 orang, $61,3 \%$, tetapi terjadi penurunan jumlah responden yang puas yang semula 55 orang atau $68 \%$ menjadi 49 orang, $61,3 \%$. Rata-rata tingkat kepuasan berdasarkan teori kebutuhan Maslow meningkat pada setiap kebutuhan. Hal ini terlihat pada tabel 2 .

Tabel 2. Kepuasan Responden berdasarkan Teori Maslow

\begin{tabular}{llrlr}
\hline $\begin{array}{c}\text { Kepuasan } \\
\text { Perawat }\end{array}$ & \multicolumn{2}{c}{$\begin{array}{c}\text { Pre } \\
\text { Intervensi }\end{array}$} & \multicolumn{2}{c}{$\begin{array}{c}\text { Post } \\
\text { Intervensi }\end{array}$} \\
\hline Tidak Puas & 25 & 31,3 & 31 & 38,8 \\
Puas & 55 & 68,8 & 49 & 61,3 \\
\hline
\end{tabular}

Rata-rata kepuasan perawat sebelum intervensi adalah 116,24 dengan standar deviasi 7,63 dan standar eror 0,85 . Sesudah intervensi rata-rata adalah 106,68 dengan standar deviasi
16,34 dan standar eror 1,82 . Terlihat perbedaan nilai rata-rata antara sebelum intervensi dengan sesudah intervensi adalah 9,56 dengan standar deviasi 17,61 dan standar eror 1,96, ada penurunan nilai rata-rata kepuasan responden. Hasil uji statistik didapatkan nilai 0,00 maka dapat disimpulkan ada perbedaan yang bermakna antara kepuasan responden sebelum dan sesudah intervensi.

Hasil penelitian menunjukkan rata-rata kepuasan berdasarkan kebutuhan menunjukkan penurunan pada semua kebutuhan. Hasil uji statistik didapatkan nilai $p$-value 0,00 maka dapat disimpulkan ada perbedaan yang bermakna antara kepuasan responden berdasarkan kebutuhan sebelum dan sesudah intervensi Terlihat perbedaan nilai rata-rata paling tinggi antara sebelum intervensi dengan sesudah intervensi yang adalah pada kebutuhan harga diri, sebesar 2,300, dan paling rendah pada kebutuhan memiliki sebesar 1,775.

Tabel 3. Perbandingan Rata-Rata Kepuasan Responden Berdasarkan Kebutuhan Antara Sebelum dan Sesudah Intervensi Overan Dengan Komunikasi SBAR

\begin{tabular}{|c|c|c|c|c|c|c|c|}
\hline Kebutuhan & Hasil & Mean & Selisih Mean & SD & SE & $\begin{array}{c}p- \\
\text { value }\end{array}$ & n \\
\hline Fisiologi & $\begin{array}{l}\text { Sebelum Intervensi } \\
\text { Sesudah Intervensi }\end{array}$ & $\begin{array}{l}22,68 \\
20,86\end{array}$ & 1,813 & 3,852 & 0,431 & 0,00 & 80 \\
\hline Rasa Aman & $\begin{array}{l}\text { Sebelum Intervensi } \\
\text { Sesudah Intervensi }\end{array}$ & $\begin{array}{l}23,38 \\
21,50\end{array}$ & 1,875 & 4,092 & 0,457 & 0,00 & 80 \\
\hline Memiliki & $\begin{array}{l}\text { Sebelum Intervensi } \\
\text { Sesudah Intervensi }\end{array}$ & $\begin{array}{l}23,70 \\
21,93\end{array}$ & 1,775 & 3,360 & 0,457 & 0,00 & 80 \\
\hline Harga Diri & $\begin{array}{l}\text { Sebelum Intervensi } \\
\text { Sesudah Intervensi }\end{array}$ & $\begin{array}{l}23,11 \\
20,81\end{array}$ & 2,300 & 3,998 & 0447 & 0,00 & 80 \\
\hline $\begin{array}{l}\text { Aktualisasi } \\
\text { Diri }\end{array}$ & $\begin{array}{l}\text { Sebelum Intervensi } \\
\text { Sesudah Intervensi }\end{array}$ & $\begin{array}{l}23,38 \\
21,58\end{array}$ & 1,800 & 3,998 & 0,447 & 0,00 & 80 \\
\hline
\end{tabular}

Hasil penelitian menunjukkan rata-rata kepuasan berdasarkan kebutuhan menunjukkan penurunan pada semua kebutuhan setelah intervensi. Hasil uji statistik didapatkan nilai 0,00 maka dapat disimpulkan ada perbedaan yang bermakna antara kepuasan responden 
berdasarkan kebutuhan sebelum dan sesudah intervensi Terlihat perbedaan nilai rata-rata paling tinggi antara sebelum intervensi dengan sesudah intervensi yang adalah pada kebutuhan harga diri, sebesar 2,300, dan paling rendah pada kebutuhan memiliki sebesar 1,775.

\section{PEMBAHASAN}

Hasil penelitian menunjukkan umur pada responden atau perawat paling banyak pada tingkat dewasa awal, masa yang seharusnya perawat bekerja dengan produktif, masa para perawat sudah mapan nmenjadi perawat, sudah mapan dengan prosedur, kondisi dan ketrampilan yang sama sehingga bila mereka mendapat kegiatan baru, mereka menjadi tidak siap. Ketrampilan baru, mengharuskan perawat belajar lagi, beradaptasi lagi, kemungkinan ini yang membuat perawat tidak siap menghadapi perubahan. Ditambah lagi, masa kerja responden sebagian besar sudah lama dan terbiasa dengan rutinitas.

Pada saat pre intervensi, kepuasan yang paling tinggi adalah pada kebutuhan aktualisasi diri. Kepuasan pada kebutuhan ini adalah karyawan merasakan pekerjaan sebagai sesuatu yang penting dan bermanfaat, dia sudah mampu bekerja dengan nyaman, percaya diri, sudah beradaptasi, karyawan puas karena mampu melaksanakan tugas dan tanggung jawabnya terhadap pekerjaan itu secara individu dan hasilnya sudah diakui rekan kerjanya, perawat merasa berhasil sebagai perawat.

Overan sebelum intervensi dilakukan tanpa komunikasi secara SBAR. Overan dilakukan di ruang perawat yang berisi pemberian informasi secara berkelompok, tidak berdasarkan diagnosa keperawatan, tapi berdasarkan diagnosa medik dan informasi kritis lainnya. Pemberian informasi diberikan oleh penanggungjawab shift kepada semua perawat yang akan bertugas. Walaupun metoda PPJP sudah dilakukan tetapi tidak ada pemberian informasi secara khusus antar perawat penanggungjawab pasien. Setelah overan di ruang perawat, overan dilakukan di sisi pasien dengan cepat dan tidak berdasarkan diagnosa keperawatan.

Bila tidak berdasarkan diagnosa maka banyak intervensi yang terlewat, perawat akan berfokus pada hal rutinitas dan intervensi mandiri perawat banyak yang tidak dilakukan. Hal ini menyebabkan mutu pelayanan keperawatan tidak baik dan juga kinerja perawat tidak terlihat.

Ketika overan dengan metoda SBAR dilakukan, perawat serah terima pasien di depan pasien dan benar-benar mengaplikasikan proses keperawatan. Kemudian peneliti dan para supervisor mulai membimbing dan memsupervisi agar proses overan sudah dengan metoda SBAR. Overan dilakukan dengan mula-mula di ruang perawat untuk mengetahi kondisi ruangan yang terkini, kemudian dilakukan di depan pasien antara PPJP dengan perawat yang bertanggungjawab melanjutkan perawatan pasiennya di shift berikutnya. Proses ini dilakukan dengan terstruktur memakai SBAR dan berbasis proses keperawatan. Pada proses ini semua kebutuhan dan tindakan pasien dapat diserahterimakan dan proses kesinambungan asuhan keperawatan bisa terjadi dengan baik antar shift. Perawat dengan mulai menyadari bahwa menguasai dan mengaplikasikan proses keperawatan itu penting dan metode overan yang terstruktur dan berbasis proses keperawatan juga menjadi faktor utama yang dibutuhkan untuk menjaga mutu pelayanan keperawatan dan keselamatan pasien dan sekaligus menunjukkan kinerja perawat itu baik. Perawat mulai terbiasa memakai proses keperawatan.

Pada saat post intervensi, kepuasan yang paling tinggi adalah kebutuhan memiliki, yaitu kepuasan akan memiliki hubungan yang positif terhadap teman kerja, atasan dan mereka merasa menjadi bagian dari tim kerja atau organisasi dan perawat mampu memelihara lingkungan kerja yang penuh kerjasama dan kerja sama sosial jadi meningkat. Kepuasan terhadap rekan kerja bisa juga dicapai karena semua perawat bisa bekerja sama, mempunyai tujuan yang jelas dan semua berusaha memberikan data yang lengkap agar perawat lain mudah bekerja. Tingkat dimana rekan kerja pandai secara teknis dan mendukung secara sosial bisa membuat suasana menyenangkan dan mempunyai rekan kerja yang menyenangkan dapat meningkatkan kepuasan kerja.

Kepuasan kebutuhan yang paling rendah pada saat pre intervensi dan pada saat post intervensi adalah kebutuhan fisiologis. Kebutuhan fisiologis adalah pada kerja di ruangan adalah faktor waktu dan tempat istirahat, makanan/minuman selama kerja, dan adanya privacy untuk perawatan diri. Ini menunjukkan bahwa metode asuhan keperawatan baik yang lama maupun yang sesuai dengan overan dengan metode SBAR, sama-sama menimbulkan kelelahan dan beban kerja yang berat bagi perawat. Mereka menganggap waktu istirahat itu terlalu ringkas. Hal inilah penyebabnya maka kepuasan pada kebutuhan ini tidak memuaskan faktor lainnya. Kepuasan 
terjadi bila tim saling menghargai, saling tahu uraian tugasnya, saling mematuhi aturan dan standar pelayanan, iklim kerja yang kondusif dan lingkungan yang memungkinkan kerja sama yang baik.

Pembahasan bivariat dilakukan dengan mengamati perbedaan kepuasan perawat dari sebelum intervensi dengan sesudahnya secara keseluruhan. Rata-rata kepuasan perawat sebelum intervensi adalah 116,24 dengan standar deviasi 7,63 dan standar eror 0,85 , sesudah intervensi rata-rata adalah 106,68 dengan standar deviasi 16,34 dan standar eror 1,82. Terlihat perbedaan nilai rata-rata antara sebelum intervensi dengan sesudah intervensi adalah 9,56 dengan standar deviasi 17,61 dan standar eror 1,96, ada penurunan nilai rata-rata kepuasan responden. Hasil uji statistik didapatkan nilai $p$-value $=0,00$ maka dapat disimpulkan ada perbedaan yang bermakna antara kepuasan responden sebelum dan sesudah intervensi. Penurunan kepuasan memang benar-benar terjadi.

Konsep yang dikemukakan Joint Commission Hospital Patient Safety, konsep overan dengan komunikasi SBAR dan sangat baik dilakukan sesuai dengan ruangan rawat inap. Overan di sisi tempat tidur memberikan kesempatan untuk memastikan komunikasi efektif antara pasien, keluarga dan perawat. Perawat merasakan manfaat yang baik dalam menggunakaan komunikasi SBAR, harapan perawat terhadap pelaksanaan komunikasi SBAR saat timbang terima agar selalu diterapkan dan di tingkatkan. Faktor pendukung dalam komunikasi SBAR berupa adanya SPO, pembekalan dan sosialisasi (Hardini \& Wahyuni, 2019). Para ahli mengatakan bahwa $70 \%$ kejadian yang tidak diinginkan terjadi karena kurangnya komunikasi antar perawat dan komunikasi antara perawat dengan pasien. Penelitian-penelitian menunjukkan bahwa overan di sisi pasien mencegah pasien jatuh dari tempat tidur pada saat overan, memperbaiki komunikasi perawat selama overan, menemukan potensial eror pada transfusi darah, kateter yang disertai infeksi dan emboli.

Overan ini meningkatkan kepuasan staf perawat dan dokter, kemampuan pengelolaan waktu dan pertanggunggugatan perawat. Overan ini memperbaiki kemampuan perawat dalam memprioritaskan tindakan dan mempersingkat waktu kerja. Melalui overan perawat mendapat imbalan secara langsung seperti penghargaan, pujian, promosi pekerjaan, ucapan dari pasien dan teman sekerja dan penghargaan terhadap profesi. Perawat bisa melaksanakan tanggungjawab secara penuh, maksimal, profesinya semakin diakui dan mendapat respon dari pasien dan tim kesehatan lain. Melalui overan, dapat dirasakan sejauh mana perhatian, bantuan teknis dan dorongan ditunjukkan oleh supervisor ketika perawat menemukan masalahmasalah yang sulit diselesaikan pada saat overan. Atasan yang memiliki hubungan personal yang baik dengan bawahan serta mau memahami kepentingan bawahan memberikan kontribusi positif bagi kepuasan perawat.

Kepuasan perawat yang lain pada overan adalah kepuasan terhadap promosi yang didapatnya atas hasil yang dicapainya untuk jenjang karir berikutnya. Kepuasan kerja akan tercapai apabila karyawan dapat mencapai tiga kedudukan psikologis yang kritis. Kedudukan psikologis tersebut yaitu pertama, karyawan merasakan pekerjaan sebagai sesuatu yang penting dan bermanfaat. Kedua, karyawan mengalami bahwa ia bertanggung jawab terhadap pekerjaan itu secara individu maupun hasil. Ketiga, karyawan dapat merasakan hasil apa yang dicapai dan apakah hasil tersebut memuaskan atau tidak.

Metode ini masih baru bagi perawat sehingga banyak yang mengeluh tentang metode ini, tapi tuntutan masa kini mengharuskan rumah sakit menjalankannya bila sudah memakai metode PPJP. Harus ada proses verifikasi tentang penerimaan informasi oleh perawat penerima dengan melakukan pengecekan dengan membaca, mengulang atau mengklarifikasi. Penerima harus mendapatkan data tentang riwayat penyakit, termasuk perawatan dan terapi sebelumnya dan overan tidak disela dengan tindakan lain untuk meminimalkan kegagalan informasi atau terlupa.

Perubahan kepuasan ini terjadi karena perawat belum menguasai overan dengan metode ini, ditambah lagi penguasaan akan proses keperawatan dituntut tinggi maka perawat merasa aktualisasinya menurun, tetapi kerja sama secara tim meningkat karena proses peralihan informasi dan kerjasama antar perawat dan shift dituntut tinggi. Hasil kepuasan pasien menurun karena perawat tidak puas dengan metode ini karena pengetahuan dan ketrampilannya kurang pada metode ini, apa lagi bila dilakukan didepan pasien dan keluarganya. Perawat merasa beban kerjanya bertambah dan proses overan menjadi lama. Konsep teori ini semakin membuktikan bahwa bila perawat melakukan overan sisi pasien akan memberikan kepuasan kepada perawat, tetapi karena metode ini bulum dilakukan maksimal, malah dianggap beban maka kepuasannya menurun. Walaupun sebenarnya nilai kepuasan perawat tetap tinggi karena pada prinsipnya prosedur overan, kemampuan perawat 
sudah prima sehingga kepuasan perawat tetap terjaga.

Handover dengan Komunikasi SBAR merupakan salah satu langkah dalam pencapaian Patient Safety yang sangat penting dilaksanakan untuk menurunkan insiden kecelakaan pasien. Penelitian kualitatif dengan pendekatan fenomenologi yang dilakukan oleh Dewi, dkk. (2019) mengatakan yaitu seringkali menghambat dan resiko tidak terlaksananya SBAR adalah perbedaan persepsi, kurangnya sosialisasi yang optimal dan motivasi belum optimal; yang menyebabkan komnikasi ini terhambat saat.

Bila dibandingkan dengan hasil penelitian sebelumnya, hasil penelitian ini bertentangan. Banyak penelitian yang menunjukkan bahwa metode overan sisi bisa menimbulkan kepuasan bagi perawat dan juga keuntungan lainnya. Penelitian yang dilakukan oleh Wakefield (2012) tentang perbandingan kepuasan pasien dan perawat sebelum dan sesudah dilakukan overan di sisi pasien menunjukkan bahwa ada peningkatan kepuasan pasien dan perawat setelah enam bulan pelaksanaan. Hasil penelitian yang dilakukan peneliti pada tahun 2016 mengenai kepuasan perawat dan kepuasan pasien sebelum dan sesudah overan sisi pasien yang menunjukkan ada perbedaan yang bermakna antara kepuasan sebelum dan sesudah metoda overan di sisi pasien dilakukan. Kepuasan perawat terhadap kinerja dan pelayanannya meningkatkan dan kepuasan pasien terhadap pelayanan dan pemulihanpasien juga meningkat. Kartika Yanidrawati (2012), mengatakan bahwa bila perawat puas, maka kinerjanya juga baik. Komunikasi yang baik dalam bekerja menimbulkan kepuasan perawat pelaksana. (Tampubolon, 2019).

Penelitian yang dilakukan oleh Bressan (2019) tentang overan sisi pasien mengatakan bahwa overan ini memudahkan pendokumentasian dan menyusun data-data yang ditemukan yang bisa dipakai untuk melakukan asuhan keperawatan di shift berikutnya. Implikasi pada manajemen keperawatan bahwa seluruh perawat sebaiknya dilatih dengan metode overan ini dan pada masa transisi perubahan dari yang tradisional dengan metode ini, perawat sebaiknya dibimbing dengan baik. Penelitian yang dilakukan oleh Sarvestani, dkk (2018) mengatakan overan ini menurunkan biaya perawatan karena menjadi strategi yang baik dalam merawat pasien. Tobiano (2018), overan sisi pasien ini berbeda dengan overan lainnya, overan ini membutuhkan pedoman-pedoman sehingga harus diperlengkapi pihak manajemen dan dilakukan terus menerus.

\section{SIMPULAN}

Kesimpulan dari penelitian ini adalah metode overan sisi pasien dengan komunikasi SBAR ini sangat baik karena bisa meningkatkan mutu pelayanan keperawatan dan kinerja perawat, sekaligus memberi kepuasan bagi perawat. Supaya berhasil, proses pembimbingan dilakukan kembali, supervisi dijalankan dan pemberian reward perlu dilakukan bila sudah berjalan. Pelatihan dan penyegaran tentang proses keperawatan sebaiknya dilakukan secara rutin agar kemampuan perawat dalam menentukan diagnosa dan intervensinya tetap prima. Secara teroritis dibuktikan bahwa komunikasi SBAR membuat proses overan bisa komprehensif sehingga bisa ditindaklanjuti di shift berikutnya. Perawat menjadi terbiasa dan merasa ini sudah membuktikan dirinya bekerja dan perawat puas dengan overan metode ini dan ini terlihat pada hasil pre-test yang menunjukkan perawat puas dengan meode ini. Perawat yang sudah mendapat pelatihan tentang metoda ini akan melakukannya dalam sehari-hari, semakin banyak dia berinteraksi dengan pasien, bertanya lebih banyak dan lebih bisa mendapatkan dan menjelaskan data perkembangan pasien. Slade (2018).

Hasil penelitian menunjukkan bahwa pada saat pre intervensi, kepuasan yang paling tinggi adalah kebutuhan aktualisasi diri, sedangkan pada saat post intervensi, kepuasan yang paling tinggi adalah kebutuhan memiliki. Kepuasan kebutuhan yang paling rendah pada saat pre intervensi dan pada saat post intervensi adalah kebutuhan fisiologis. Rata-rata kepuasan perawat sebelum intervensi sudah dalam kategori baik. Sesudah intervensi rata-rata juga kategori baik. Terlihat perbedaan nilai rata-rata antara sebelum intervensi dengan sesudah intervensi walaupun ada penurunan nilai rata-rata kepuasan responden walaupun masih dalam ketegori baik. Hasil uji statistik didapatkan nilai 0,00 maka dapat disimpulkan ada perbedaan yang bermakna antara kepuasan responden sebelum dan sesudah intervensi. 


\section{DAFTAR PUSTAKA}

Basri, B. (2018). Hubungan Supervisi Kepala Ruangan Terhadap Kepuasan Kerja Perawat Pelaksana Di Rumah Sakit Imelda Medan. Jurnal maternitas Kebidanan, 3(2), 91-106.

Bressan, V., Cadorin, L., Pellegrinet, D., Bulfone, G., Stevanin, S., \& Palese, A. (2019). Bedside shift handover implementation quantitative evidence: Findings from a scoping review. Journal of nursing management, 27(4), 815-832.

Dewi, M. (2012). Pengaruh pelatihan timbang terima pasien terhadap penerapan keselamatan pasien oleh perawat pelaksana di RSUD Raden Mattaher Jambi. Jurnal Health and Sport, 5(03).

Dewi, R., Rezkiki, F., \& Lazdia, W. (2019). Studi Fenomenology Pelaksanaan Handover Dengan Komunikasi SBAR. Jurnal Endurance: Kajian Ilmiah Problema Kesehatan, 4(2), 350-358.

Donna L. B. Zarro, et al. (2007). Improving Nursing Handoff During Change of Shift. Australia Journal of Advanced Nursing, Volume 30 Number 1.

Hardini, S., \& Wahyuni, F. S. (2019). Studi Fenomenologi: Pelaksanaan Komunikasi SBAR pada saat Timbang Terima di Bangsal Bedah dan Interne RSUP Dr. M. Djamil Padang. Jurnal Kesehatan Medika Saintika, 10(2), 53-63.

Hastono. P. S. (2007). Analisa Data Kesehatan. Fakultas Kesehatan Masyarakat, Universitas Indonesia.

Malfait, S., Van Hecke, A., Van Biesen, W., \& Eeckloo, K. (2018). Do Bedside Handovers Reduce Handover Duration? An Observational Study With Implications for Evidence-Based Practice. Worldviews on Evidence-Based Nursing, 15(6), 432439.

Notoatmodjo, S. (2012). Metodologi Penelitian Kesehatan. Edisi Revisi. Jakarta: Rineka Cipta.

Nursalam. (2011). Manajemen Keperawatan. Edisi 3. Jakarta: Salemba.
Sarvestani, R. S., Jafari, A., \& Moattari, M. (2018). Cost effectiveness of nursing handover: an action research. Nurse Care Open Acces J, 5(6), 343-346.

Samakori, H. S. (2019). Hubungan kepatuhan perawat dalam handover antar shift terhadap keselamatan pasien di ruang rawat inap rs umum bhakti rahayu kota surabaya. [Skripsi]. Surabaya: Universitas Merdeka Surabaya.

Slade, D., Pun, J., Murray, K. A., \& Eggins, S. (2018). Benefits of health care communication training for nurses conducting bedside handovers: An Australian hospital case study. The Journal of Continuing Education in Nursing, 49(7), 329-336.

Sumartyawati, N. M. (2018). Hubungan pelaksanaan supervisi dengan kepuasan kerja perawat pelaksana di instalansi rawat inap RSUD Patut Patuh Patju Kabupaten Lombok Barat. PrimA: Jurnal Ilmiah Ilmu Kesehatan, 4(2).

Tampubolon, P. L. (2019). Hubungan Komunikasi Organisasi dengan Kinerja dan Kepuasan Perawat Pelaksana di Ruang Rawat Inap Rumah Sakit Royal Prima Medan Tahun 2017. [Tesis]. Medan: Fakultas Keperawatan, Universitas Sumatera Utara.

Tobiano, G., Bucknall, T., Sladdin, I., Whitty, J. A., \& Chaboyer, W. (2018). Patient participation in nursing bedside handover: a systematic mixed-methods review. International journal of nursing studies, 77, 243-258.

Wakefield, D. S., Ragan, R., Brandt, J., \& Tregnago, M. (2012). Making the transition to nursing bedside shift reports. The Joint Commission Journal on Quality and Patient Safety, 38(6), 243AP1.

Yanidrawati, K. (2012). Hubungan kepuasan kerja dengan kinerja perawat di ruang rawat inap rumah sakit umum daerah kabupaten bekasi. Students e-Journal, 1(1), 32. 